\title{
Low-Dose Cold Atmospheric Plasma Promoting Schwann Cells Proliferation By Activating PI3K/Akt/mTOR Pathway
}

\section{Bibo Ge}

Department of Orthopaedics, the Second Affiliated Hospital of Anhui Medical University

\section{Jie Bao}

Anhui Province Key Laboratory of Medical Physics and Technology, Institute of Health \& Medical Technology, Hefei Institutes of Physical Science, Chinese Academy of Sciences

Jinwu Chen

Anhui Province Key Laboratory of Medical Physics and Technology, Institute of Health \& Medical Technology, Hefei Institutes of Physical Science, Chinese Academy of Sciences

\section{Xinzhong Xu}

Department of Orthopaedics, the Second Affiliated Hospital of Anhui Medical University

Juehua Jing

Department of Orthopaedics, the Second Affiliated Hospital of Anhui Medical University

\section{Wencheng Song}

Anhui Province Key Laboratory of Medical Physics and Technology, Institute of Health \& Medical Technology, Hefei Institutes of Physical Science, Chinese Academy of Sciences

Chungui Xu ( $\nabla$ xcg1984@bjmu.edu.cn )

the Second Affiliated Hospital of Anhui Medical University

\section{Research Article}

Keywords: Cold atmospheric plasma, Peripheral nerve injury, Schwann cells, ROS, RNS

Posted Date: June 23rd, 2021

DOI: https://doi.org/10.21203/rs.3.rs-598902/v1

License: (c) (i) This work is licensed under a Creative Commons Attribution 4.0 International License. Read Full License 


\section{Abstract}

Cold atmospheric plasma (CAP) is an emerging technology that has attracted the attention of many researchers in many fields and disciplines. In this study, a dielectric barrier discharge (DBD) plasma device was used to treat Schwann cells (SCs) cultured in vitro, and the effect of CAP on SCs proliferation was evaluated by cell morphology, cell viability, cell cycle and expression of related proteins in SCs. The results showed that the production of intracellular ROS and RNS increased with the increase of CAP treatment time. Compared with the control group, the proliferation of SCs treated with CAP for less than $14 \mathrm{~s}$ significantly increased, and and then gradually decreased. Besides, the cell cycle results also showed that more cells were in the $\mathrm{S}+\mathrm{G} 2 / \mathrm{M}$ phase at this time.The PI3K/Akt/mTOR pathway was activated by low-dose CAP, and the expression of cyclinD1 was consistent with the trend of cell proliferation. In addition, n-acetyl-L-cysteine (NAC) preconditioning significantly prevented CAP-induced cellular changes. In conclusion, low-dose CAP-induced of SCs proliferation was closely related to the PI3K/Akt/mTOR signaling pathway. This study provides a new idea for the treatment of peripheral nerve injury.

\section{Introduction}

Plasma is a fourth state of matter distinct from solids, liquids and gases. Studies have shown that plasma contains a variety of physical and chemical components (Juliana Šimončicová et al., 2019, Kartaschew et al., 2015). Traditional plasma cannot be used for biomedicine for its high temperature. Fortunately, the emergence of cold atmospheric plasma (CAP) has solved this problem. CAP is a new biomedical treatment method that has been applied in disinfection (O'Connor et al., 2014, Izadjoo et al., 2018), wound healing (Haertel et al., 2014, Wiegand et al., 2017), stomatology (Hartwig et al., 2017, Hoffmann et al., 2013), skin diseases (Gan et al., 2018) and tumor therapy (Yan et al., 2017, Semmler et al., 2020). The anticancer ability of high-dose CAP has always been the focus of researchers (Xu et al., 2020, Haralambiev et al., 2020). However, the proliferation effect of low-dose CAP has also attracted more and more researchers' attention in recent years (He et al., 2020, Duchesne et al., 2019). Studies have shown that low-dose CAP can effectively promote the proliferation of epithelial cells (Dezest et al., 2017), immune cells (Azzariti et al., 2019) and fibroblasts (Miletić et al., 2013). Although CAP has been applied in a variety of medical regeneration fields, the potential of CAP in the field of nerve regeneration has not been explored and is worth further study.

Peripheral nerve injury can be divided into nerve conduction dysfunction, nerve axon interruption and nerve fracture according to the degree of injury (Ching and Kingham, 2015). In nerve conduction dysfunction, nerve fibers have no structural changes, so patients only present with temporary sensorimotor disorder, which can recover by itself in a short time. In the interruption of axon and fracture of nerve, the continuity of axon, the main structure of nerve electrical signal conduction, is interrupted. The distal end of the broken axonal loses the nourishment of the proximal cell body and leads to degeneration, demyelination and degradation, which is called Wallerian degeneration (Conforti et al., 2014). SCs are important cells that maintain the stability of the normal nerve internal environment and promote the regeneration of peripheral nerve after injury. SCs provide nutrients for axon development, 
maturation and regeneration, and are the main cell type responsible for myelin sheath axons in the peripheral nervous system (Jessen and Mirsky, 2016). As an important pathway for SCs development, the $\mathrm{PI3K} / \mathrm{Akt} / \mathrm{mTOR}$ pathway plays an important role in promoting autophagy (Gao et al., 2019) and remyelination (Ishii et al., 2019) of SCs after peripheral nerve injury. Phenotypic changes occurred after SCs were separated from axons to dedifferentiate and proliferate. Meanwhile, secreting factors induced macrophages to gather at the damaged sites and activate, and phagocytosis and clearance of degraded axon and myelin fragments together with SCs (Chen et al., 2015). With the clearance of degenerative tissues, macrophages secrete vascular endothelial cell growth factor, promote the growth of new blood vessels into the nerve fracture end, and guide SCs to form a hollow tubular structure, laying the foundation for the growth of new axial buds (Cattin et al., 2015). In the process of regeneration of peripheral nerve degeneration, SCs play an important role in guiding axonal growth and remyelin by secreting various factors and communicating with neurons, macrophages and other cells (Namgung, 2014). At present, the treatment and research of peripheral nerve injury repair still mainly stay at the suture technology level of various anastomosis (Li et al., 2014), nerve transplantation (Rbia and Shin, 2017), artificial nerve bridging (Safa and Buncke, 2016), etc. However, the actual clinical effect of nerve injury patients is not satisfactory. Therefore, it is imperative to propose a new therapy for peripheral nerve injury.

In this study, a DBD plasma device was used to treat SCs cultured in vitro, and the effect of CAP on SCs proliferation was evaluated by cell morphology, cell viability, cell cycle and expression of related proteins in SCs. At the same time, the mechanism of CAP on the proliferation of SCs were observed by the increase or decrease of the expression of related proteins. This study will provide a new way of thinking for clinical treatment of peripheral nerve injury.

\section{Materials And Methods}

\subsection{Cell culture}

The SCs lines RSC96 were obtained from the Cell Bank of the Chinese Academy of Sciences (Shanghai, China). All cells were cultured in DMEM (Thermo Scientific, USA) supplemented with $10 \%$ fetal bovine serum (Sigma-Aldrich, USA) and 1\% penicillin-streptomycin (Sangon Biotech, Shanghai, China). Cells were incubated in a cell incubator at $37{ }^{\circ} \mathrm{C}$ with $5 \% \mathrm{CO}_{2}$. The cell growth was observed regularly under an inverted microscope.

\subsection{Discharge apparatus}

The plasma device used in this study is a DBD plasma device. The DBD plasma device is composed of a hollow plexiglass with air inlets and outlets as the reactor chamber. The ground electrode is a copper cylinder with a diameter of $60 \mathrm{~mm}$, the high voltage electrode is a copper cylinder with a diameter of 38 $\mathrm{mm}$, and the quartz glass is covered with $1 \mathrm{~mm}$ thickness as the dielectric barrier. Similar types of configuration have been reported in other articles (Zhang et al., 2020a, Song et al., 2018). In our experiment, the working gas Helium (purity of $99.99 \%$ ) with a flow rate of $1.0 \mathrm{~L} / \mathrm{min}$ was supplied to the 
reactor chamber. The reactor chamber is a cylinder with a base diameter of $18 \mathrm{~cm}$ and a height of $3 \mathrm{~cm}$. The DBD plasma experimental setup is described in Fig. 1A. Before the plasma discharge, the working gas is injected into the reactor chamber for $90 \mathrm{~s}$ to eliminate the residual air in the chamber as much as possible. Then, an alternating voltage was applied on the DBD plasma device. Cell samples covered with $5 \mathrm{~mL}$ culture medium were treated with plasma and irradiated in the reactor for different time $(7 \mathrm{~s}, 14 \mathrm{~s}$,

$21 \mathrm{~s}, 28 \mathrm{~s}$ ). Before subsequent detection and analysis, the treated cells were incubated for 24 hours. The control group ( $0 \mathrm{~s})$ was untreated, but other conditions were the same. The voltage and current waveforms of Helium discharge in the alternating voltage DBD plasma device are shown in Fig. 1B. The waveform measured by the oscilloscope is a sine wave with a frequency of $2.5 \mathrm{kHz}$, and the rms values of voltage and current were $3.82 \mathrm{kV}$ and $33 \mathrm{~mA}$, respectively.

\subsection{Detection of ROS and RNS in DMEM}

In this study, $\mathrm{H}_{2} \mathrm{O}_{2}$ detection kit (Beyotime, Shanghai, China) and NO detection kit (Beyotime, Shanghai, China) were used to detect the liquid phase $\mathrm{H}_{2} \mathrm{O}_{2}$ and nitric oxide (NO) generated by DBD plasma respectively, and the operation was performed in accordance with the kit instructions. Standard well and sample well were set as follows: the standard well was added with $50 \mu \mathrm{L}$ standard of different concentrations according to the gradient, and $50 \mu \mathrm{L}$ sample to be tested was added into the sample well. When detecting $\mathrm{H}_{2} \mathrm{O}_{2}, 100 \mu \mathrm{L}$ of $\mathrm{H}_{2} \mathrm{O}_{2}$ detection reagent was added to each well. When detecting NO, 50 $\mu \mathrm{L}$ of Griess Reagents $\nabla$ and $50 \mu \mathrm{L}$ of Griess Reagents $\otimes$ were added to each well respectively, and placed at room temperature for $30 \mathrm{~min}$. Then the Optical Density (OD) value of each well was measured at 540 $\mathrm{nm}$ wavelength with a microplate reader.

\subsection{Detection of intracellular ROS and RNS}

The production of ROS and NO in cells was determined by DCFH-DA (Beyotime, Shanghai, China) and DAF-FMDA (Beyotime, Shanghai, China), respectively. After the CAP treatment, the cells were cultured for 24 hours, the cell culture medium was removed before the determination, and washed with PBS for 3 times. Both probes were diluted in serum-free medium at a ratio of 1:1000. Add an appropriate volume of diluted probes, and the added volume should be sufficient to cover the cells. The cells were incubated in incubator at $37{ }^{\circ} \mathrm{C}$ for $30 \mathrm{~min}$, and then washed with serum-free cell culture solution for 3 times to fully remove the redundant probes. Then the cells were collected and detected with a fluorescence microplate reader. For ROS, the wavelength is set to $488 \mathrm{~nm}$ excitation wavelength and $525 \mathrm{~nm}$ emission wavelength. For NO, the wavelength is set to $495 \mathrm{~nm}$ excitation wavelength and $515 \mathrm{~nm}$ emission wavelength.

\subsection{Cell viability assay}

The SCs viability after CAP treatment was measured by CCK-8 kit (Beyotime, Shanghai, China) following the instructions. Cells pretreated with CAP for different time $(0 \mathrm{~s}, 7 \mathrm{~s}, 14 \mathrm{~s}, 21 \mathrm{~s}, 28 \mathrm{~s})$ were added into a 96-well plate at a density of 5000 cells/well and cultured for $24 \mathrm{~h}$. Then the old medium was removed and washed with PBS for 3 times. Add $100 \mu \mathrm{L}$ ordinary DMEM high glucose medium and $10 \mu \mathrm{L}$ CCK-8 solution to each well, and incubate at $37^{\circ} \mathrm{C}$ for 2 hours. Finally, the OD value of each well was measured 
at $450 \mathrm{~nm}$ wavelength. The OD value of each test hole was subtracted from the blank hole OD value, and the $\mathrm{OD}$ value of each repeat hole was averaged.

Cell viability $(\%)=(O D$ exp - OD blank $) /(O D$ ctrl - OD blank $) \times 100 \%$.

\subsection{Flow Cytometry analysis of cell cycle}

CAP treated cells were cultured for 24 hours, the old medium was removed and rinsed with PBS for 3 times. The cells were removed with trypsin without EDTA (Sangon Biotech, Shanghai, China). The cell suspension was collected in a centrifuge tube and the cells were sufficiently precipitated by centrifugation. The supernatant was disposed and about $1 \mathrm{~mL}$ of cold PBS was added to resuspend the cells. The cells were centrifuged again, disposed of the supernatant, and then the bottom of the centrifuge tube was gently shaken to properly disperse the cells to avoid cell clumping. The cells were washed twice by cold PBS, then mixed with $70 \%$ cold ethanol and fixed at $4{ }^{\circ} \mathrm{C}$ for at least 4 hours. After incubation, $0.5 \mathrm{~mL}$ propidium iodide staining solution was added to each sample, then the cells were fully resuspended and incubated at $37^{\circ} \mathrm{C}$ for 30 min without light. Lastly, cells were detected by Flow cytometry within 24 hours after staining.

\subsection{Western blot}

After CAP treatment, the cells were cultured for 24 hours. Protein samples were extracted from the cells with RIPA buffer, and then SDS-PAGE protein loading buffer was added and heated at $100^{\circ} \mathrm{C}$ for 10 min. The proteins were separated on $10 \%$ SDS-PAGE, electrophoresis transferred to nitrocellulose (NC) membrane, and then blocked with Tris-buffered saline (TBST) buffer and $5 \%$ skim milk powder for 2 hours at room temperature. After blocking, the primary antibody was incubated at $4{ }^{\circ} \mathrm{C}$ overnight. After washing 3 times with TBST, the secondary antibody horseradish peroxidase was incubated on the membrane at room temperature for 1 hour. After washing 3 times with TBST, the blot was exposed in a dark room using an ECL western blotting chemiluminescent substrate kit (Thermo Scientific, USA). The film was scanned and the gray value of the target band was analyzed by ImageJ software.

\subsection{Statistical analysis}

Each experiment was separately repeated 3 times, and the results were expressed as mean \pm standard deviation. The results obtained under different experimental conditions were analyzed by one-way ANOVA, and the differences were considered to be statistically significant when $p<0.05$.

\section{Results}

\section{1. $\mathrm{H}_{2} \mathrm{O}_{2}$ and $\mathrm{NO}$ in DMEM}

The effect of plasma on cells studied in this experiment is mainly mediated by liquid phase, so it is necessary to evaluate the generation of $\mathrm{H}_{2} \mathrm{O}_{2}$ and $\mathrm{NO}$ in DMEM induced by plasma. The concentrations of $\mathrm{H}_{2} \mathrm{O}_{2}$ and $\mathrm{NO}$ in DMEM were detected immediately after CAP treatment for different times $(0 \mathrm{~s}, 7 \mathrm{~s}, 14$ 
s, $21 \mathrm{~s}, 28 \mathrm{~s}$ ). The results are shown in the Fig. $2 \mathrm{~A}$ and 2B. The concentration of $\mathrm{H}_{2} \mathrm{O}_{2}$ and $\mathrm{NO}$ increased significantly with the plasma treatment time. After $28 \mathrm{~s}$ of plasma irradiation, the concentrations of $\mathrm{H}_{2} \mathrm{O}_{2}$ and NO increased to $151.55 \mu \mathrm{M}$ and $33.67 \mu \mathrm{M}$, respectively, which were 10.4 times and 4.6 times that of the control group. It was proved that there were a large amount of $\mathrm{H}_{2} \mathrm{O}_{2}$ and NO production in DMEM after plasma treatment.

\subsection{Intracellular ROS and NO}

Plasma irradiation can cause the accumulation of ROS and NO in cells, which can make a difference to cell viability and cell cycle. We measured the levels of ROS and NO in cells after plasma irradiation for different times. As shown in the Fig. $2 \mathrm{C}$ and 2D, with the extension of plasma treatment time, the concentration of ROS and NO increased significantly. It can be seen that CAP can induce the production of ROS and NO in a time-dependent manner. After $14 \mathrm{~s}$ of CAP treatment, intracellular ROS and NO increased by 1.98 times and 1.30 times respectively compared with the control group. Besides, the production of intracellular ROS and NO increased rapidly compared with the control group, and the production of ROS and NO increased by 4.81 times and 3.73 times at $28 \mathrm{~s}$, respectively.

\subsection{CAP affects cell morphology}

In Fig. 3, it was observed that CAP treatment changed the morphology of SCs. Compared with control, there was no significant change in cell morphology after $7 \mathrm{~s}$ and $14 \mathrm{~s}$ of treatment with CAP. After $21 \mathrm{~s}$, the cells shrank and a small number of cells were suspended in the cell culture medium. When the treatment time reached $28 \mathrm{~s}$, the previously spindle-shaped cells became round and shrink, and more cells were suspended in the culture medium.

\subsection{CAP-triggered changes in cell viability}

In order to verify the effect of CAP on the viability of SCs, we treated the cells of each group with different exposure times $(0 \mathrm{~s}, 7 \mathrm{~s}, 14 \mathrm{~s}, 21 \mathrm{~s}, 28 \mathrm{~s})$, and then the changes in cell viability were analyzed by the CCK8 detection kit. As shown in Fig. 4, compared with the control group, the survival rate of cells was significantly increased with the increase of treatment time $(p<0.05)$, and a peak value was observed at $14 \mathrm{~s}$. However, when the treatment time reached $28 \mathrm{~s}$, the OD value decreased significantly. Therefore, $14 \mathrm{~s}$ CAP treatment was selected as a low-dose CAP study to promote SCs cell proliferation.

\subsection{CAP-triggered changes in cell cycle distribution}

Cell cycles of each group of cells treated by CAP with different exposure times $(0 \mathrm{~s}, 7 \mathrm{~s}, 14 \mathrm{~s}, 21 \mathrm{~s}, 28 \mathrm{~s})$ were analyzed by flow cytometry. As shown in the Fig. 5, the proportion of $S+G 2 / M$ phase cells increased significantly with the increase of CAP irradiation time. The results of quantitative analysis showed that the proportion of $S+G 2 / M$ phase cells was $24.3 \%$ in the control group, and the percentage of $S+G 2 / M$ phase cells in the $14 \mathrm{~s}$ CAP group was $27.5 \%$, which was a significant difference $(p<0.05)$. This results showed that low-dose CAP treatment could promote more cells from G0/G1 phase to $S+G 2 / M$ phase.

\subsection{Protein expression in CAP-treated Schwann cells}


$\mathrm{PI} 3 \mathrm{~K} / \mathrm{Akt} / \mathrm{mTOR}$ is an important intracellular signal pathway regulating SCs, which is directly related to cell growth and development. In order to determine whether CAP can activate SCs in vitro, the key molecules of PI3K/AKT/mTOR pathway in SCs cells before and after CAP treatment were performed by western blot detection. As seen in Fig. 6, compared with the control group, the protein expression gradually increased in the $14 \mathrm{~s}$ treatment group $(\mathrm{p}<0.05)$. Furthermore, for the $14 \mathrm{~s}$ treatment group, 5 mM NAC was used to remove ROS induced by CAP in DMEM, and the related proteins were also detected by western blot. Compared with the control group, there is no significant change in protein expression. It is suggested that CAP-induced ROS is closely related to the activity of PI3K/Akt/mTOR pathway.

Besides, cyclinD1 plays an important role in cell cycle regulation, which promotes cells from $\mathrm{G} 1$ phase into $S$ phase and initiates DNA replication. We detected the expression of cyclinD1 by western blot and found that compared with the control group, the expression of cyclinD1 in the $14 \mathrm{~s}$ group gradually increased $(p<0.05)$, while the expression of cyclinD1 in the NAC group did not change significantly. This result suggests that low-dose CAP treatment can promote the expression of cyclinD1 and promote more cells from $\mathrm{G} 1$ phase to $S$ phase.

\section{Discussion}

When peripheral nerve injury, the cell body cannot provide nutritional support to the axons on the distal side of the broken end. At this time, Waller degeneration may occur (Conforti et al., 2014). In Wallerian degeneration, SCs are initially involved in the peripheral nerve regeneration process. After peripheral nerve injury, SCs began to proliferate. The number of SCs peaked 1 to 2 weeks after peripheral nerve injury, and then decreased. Together with SCs, macrophages phagocyte the myelin sheath of the deformed axons, and the SCs form Bungner bands, which promote axon growth. SCs can also secrete bioactive substances, such as nerve cell adhesion molecules and neurotrophic factors. It not only induces nerve reinnervation and myelination, but also stabilizes the network of peripheral glial cells, and promotes the myelination of new axons by means of temporary adhesion. The functions of SCs after peripheral nerve injury are diverse. They not only have the function of phagocytosis, but also provide scaffolds and neurotrophic factors for nerve regeneration, maintain the survival of neurons, guide the orderly extension of axons, promote the myelination of axons, and regulate the survival and apoptosis of the axons (Conforti et al., 2014). The function of SCs is so powerful that if the proliferation of SCs can be promoted when the nerves is damaged, it must speed up the repair of peripheral nerves. Although many studies have investigated the effect of CAP on cell proliferation (Kalghatgi et al., 2010, Liu et al., 2017, Duchesne et al., 2019, Sardella et al., 2020, Arndt et al., 2013, Lou et al., 2020, Kleineidam et al., 2019, Hasse et al., 2016), the relationship between CAP and cell behavior in the field of nerve regeneration, especially in the field of peripheral nerve regeneration, is still unclear. In this study, we choose SCs, which is an important cell that maintains the stability of the normal neural internal environment, as the research object. The effect of CAP on SCs proliferation was evaluated by cell morphology, cell viability, cell cycle and expression of related proteins in SCs. 
The method proposed in this study was based on exposure of cells to the culture medium treated with CAP. In the culture medium treated by CAP, the effects of some less stable or less content substances, such as $\mathrm{ONOO}^{-} \square \mathrm{O}_{3} \square \mathrm{O}_{2}{ }^{-}$, are negligible compared with other stable substances produced. This is due to its preferred reaction with the composition of the medium at neutral pH (Tarabova et al., 2019). Rezaei et al. also showed that $\mathrm{H}_{2} \mathrm{O}_{2}$ and $\mathrm{NO}$ could be used as markers for all ROS and RNS species produced by CAP due to their stability and long effectiveness, although other ROS and RNS were present in the culture medium treated by CAP (Rezaei et al., 2019). In addition, the quantitative detection results of intracellular free radicals were difficult to obtain accurately with the current technology, and the concentration of free radicals could not be quantified (Kalyanaraman et al., 2017).Therefore, in this study, a common fluorescent probe was used to reflect the changing trend of free radicals, and the relative fluorescence intensity of each experimental group was analyzed with a fluorescence microplate reader to reflect the changing trend of intracellular ROS and RNS with the processing time. In fact, whether it was intracellular ROS and RNS or extracellular ROS and RNS, its amount was always positively correlated with processing time, which was consistent with the results of most researchers (Song et al., 2018, Liu et al., 2017, Xu et al., 2020, Zhang et al., 2020a).

ROS is a kind of oxygen-containing substance produced by aerobic cells in the process of aerobic metabolism, it has extremely high biological activity, and plays an important role in cell proliferation and apoptosis (Luo et al., 2019, Mo et al., 2019, Zhang et al., 2020b). A certain amount of intracellular ROS is necessary to maintain the normal physiological state of the cell (Forrester et al., 2018, Sies and Jones, 2020). However, high concentration of ROS can lead to oxidative stress and damage of DNA, protein and membrane in cells, leading to cell death (Sun et al., 2019, Nissanka and Moraes, 2018). As a special molecule, NO acts as a biological messenger in the body, transmitting information from nerves to cells, and Endogenous NO plays a role in regulating cellular function and messenger in health (Qi et al., 2020, Oláh et al., 2018, Xu et al., 2015). It is very meaningful to note that low concentrations of NO are beneficial to human health, but high concentrations are harmful (Islam, 2017, Zhang et al., 2017). The experimental results in this study confirm these views, the double effect of CAP on SCs was also proved by cell viability. The results showed that low-dose CAP could promote SCs proliferation, but high-dose CAP inhibite the growth of SCs, which was consistent with the effect of CAP treatment on many normal cells (Boehm et al., 2016, Xu et al., 2015, Hasse et al., 2016, Liu et al., 2017, Lou et al., 2020, Sardella et al., 2020, Kalghatgi et al., 2010, Kleineidam et al., 2019, Arndt et al., 2013). Besides, results proved that appropriate CAP treatment could promote the transformation of cells from G0/G1 phase to $S+G 2 / M$ phase by cell cycle, thus promoting the proliferation of SCs.

SCs are the main glial cells of the peripheral nervous system to form the myelin sheath and realize the jump conduction of action potential (Castelnovo et al., 2017). They also secrete neurotrophic factors, which promote the survival of damaged neurons and the regeneration of axons, and participate in the formation of nerve fibers in the peripheral nervous system (Jessen and Mirsky, 2016, Feltri et al., 2016). For example, NRG-1/ErbB signaling is an important pathway for SCs development, and NRG-1/ErbBmediated activation of the PI3K pathway converts phosphatidylinositol diphosphate (PIP2) to 
phosphatidylinositol triphosphate (PIP3), then activating Akt (Park et al., 2008, Castelnovo et al., 2017). Other studies supported the importance of this pathway in SCs development (Ogata et al., 2006, Maurel and Salzer, 2000). Besides, the activity of PI3K is not only affected by ErbB signaling, but also affected by ROS (Chen et al., 2017, Yao et al., 2020), thus affecting the transformation of PIP2 to PIP3. In addition, some studies have shown that CAP-treated cells can increase ROS production and alter the expression of cyclinD1, thereby altering cell cycle progression (Liu et al., 2017, Zhang et al., 2020a). In this study, ROS produced by CAP activates PI3K, which converts PIP2 to PIP3, and activates Akt. Then, Akt activates cyclinD1 and mTOR respectively, which promotes cell cycle progression and cell proliferation at the same time. The specific process is shown in the Fig. 7. NAC preconditioning significantly inhibited the activation of PI3K/Akt/mTOR pathway, and also inhibited the change of cyclinD1 expression induced by CAP. The results showed that CAP can activate the PI3K/Akt/mTOR pathway at appropriate dose, and we speculate that the mechanism is closely related to CAP-induced ROS production.

In fact, many plasma sources with various design have been proposed for biomedical applications, but the relationship between source characteristics and application performance is not well-understood. This prevents researchers to directly compare different plasma sources to study the effect of plasma dose.. Therefore, in this study, we used the treatment time as the only variable to control the concentration of ROS and RNS produced by CAP. The effect of active substances produced by CAP on living cells is very complex, the properties and concentrations of active substances formed after CAP treatment may vary widely, which depends on the type of gas used in the experiment, the experimental apparatus (type of plasma reactor, e.g. DBD plasma or jet plasma), the voltage of the discharge apparatus and the type of

plasma activated liquid (Przekora et al., 2019, Hasse et al., 2016, GÜMBEL et al., 2017). These parameters not only changed CAP-induced ROS, but also changed the effect of electromagnetic field radiation on cell proliferation in vitro. Therefore, maintaining other parameters unchanged, choosing time as the only variable can simply and effectively control the plasma dose problem. The experimental results also showed that the concentrations of ROS and RNS produced by CAP were obviously time-dependent when other parameters were maintained unchanged. Although some of the mechanisms discussed in this study could explain the regulation of CAP on SC proliferation, further studies are needed for clinical application of this technique.

\section{Conclusion}

In this study, a DBD plasma device was used to treat SCs, and the effect of CAP on SCs proliferation was evaluated by cell morphology, cell viability, cell cycle and expression of related proteins in SCs. Our observations show that low level of ROS was critical for cell proliferation, but harmful at high ROS concentrations. Besides, SCs proliferation capacity reached the peak when CAP was treated for $14 \mathrm{~s}$, and the cell cycle results also showed that more cells were in the $S+G 2 / M$ phase at this time. Our results suggest that low-dose CAP may enhance the proliferation of SCs by accelerating cell cycle and activating $\mathrm{PI} 3 \mathrm{~K} / \mathrm{Akt} / \mathrm{mTOR}$ pathway. This study reveals the possible mechanism of CAP promoting SCs proliferation, and also provides a new idea for the treatment of peripheral nerve injury. 


\section{Declarations}

Acknowledgments: The program was supported by National Natural Science Foundation of China (21876179), China Postdoctoral Science Foundation Funded Project (2020T130117ZX and 2020M671914), and Funds for Research Activities of Anhui Postdoctoral Researchers (2020B470).

\section{References}

1. Arndt, S., Unger, P., Wacker, E., Shimizu, T., Heinlin, J., Li, Y. F., Thomas, H. M., Morfill, G. E., Zimmermann, J. L., Bosserhoff, A. K. \& Karrer, S. 2013. Cold atmospheric plasma (CAP) changes gene expression of key molecules of the wound healing machinery and improves wound healing in vitro and in vivo. PLoS One, 8, e79325.

2. Azzariti, A., lacobazzi, R. M., Di Fonte, R., Porcelli, L., Gristina, R., Favia, P., Fracassi, F., Trizio, I., Silvestris, N., Guida, G., Tommasi, S. \& Sardella, E. 2019. Plasma-activated medium triggers cell death and the presentation of immune activating danger signals in melanoma and pancreatic cancer cells. Sci Rep, 9, 4099.

3. Boehm, D., Heslin, C., Cullen, P. J. \& Bourke, P. 2016. Cytotoxic and mutagenic potential of solutions exposed to cold atmospheric plasma. Sci Rep, 6, 21464.

4. Castelnovo, L. F., Bonalume, V., Melfi, S., Ballabio, M., Colleoni, D. \& Magnaghi, V. 2017. Schwann cell development, maturation and regeneration: a focus on classic and emerging intracellular signaling pathways. Neural Regen Res, 12, 1013-1023.

5. Cattin, A. L., Burden, J. J., Van Emmenis, L., Mackenzie, F. E., Hoving, J. J., Garcia Calavia, N., Guo, Y., Mclaughlin, M., Rosenberg, L. H., Quereda, V., Jamecna, D., Napoli, I., Parrinello, S., Enver, T., Ruhrberg, C. \& Lloyd, A. C. 2015. Macrophage-Induced Blood Vessels Guide Schwann Cell-Mediated Regeneration of Peripheral Nerves. Cell, 162, 1127-1139.

6. Chen, L., Liu, P., Feng, X. \& Ma, C. 2017. Salidroside suppressing LPS-induced myocardial injury by inhibiting ROS-mediated PI3K/Akt/mTOR pathway in vitro and in vivo. J Cell Mol Med, 21, 31783189.

7. Chen, P., Piao, X. \& Bonaldo, P. 2015. Role of macrophages in Wallerian degeneration and axonal regeneration after peripheral nerve injury. Acta Neuropathol., 130, 605-618.

8. Ching, R. C. \& Kingham, P. J. 2015. The role of exosomes in peripheral nerve regeneration. Neural Regen Res, 10,743-747.

9. Conforti, L., Gilley, J. \& Coleman, M. P. 2014. Wallerian degeneration: an emerging axon death pathway linking injury and disease. Nat Rev Neurosci, 15, 394-409.

10. Dezest, M., Chavatte, L., Bourdens, M., Quinton, D., Camus, M., Garrigues, L., Descargues, P., Arbault, S., Burlet-Schiltz, O., Casteilla, L., Cl F-Ment, F., Planat, V. \& Bulteau, A. L. 2017. Mechanistic insights into the impact of Cold Atmospheric Pressure Plasma on human epithelial cell lines. Sci Rep, 7, 41163. 
11. Duchesne, C., Banzet, S., Lataillade, J. J., Rousseau, A. \& Frescaline, N. 2019. Cold atmospheric plasma modulates endothelial nitric oxide synthase signalling and enhances burn wound neovascularisation. J Pathol, 249, 368-380.

12. Feltri, M. L., Poitelon, Y. \& Previtali, S. C. 2016. How Schwann Cells Sort Axons: New Concepts. Neuroscientist, 22, 252-265.

13. Forrester, S. J., Kikuchi, D. S., Hernandes, M. S., Xu, Q. \& Griendling, K. K. 2018. Reactive Oxygen Species in Metabolic and Inflammatory Signaling. Circ Res, 122, 877-902.

14. Gan, L., Zhang, S., Poorun, D., Liu, D., Lu, X., He, M., Duan, X. \& Chen, H. 2018. Medical applications of nonthermal atmospheric pressure plasma in dermatology. J Dtsch Dermatol Ges, 16, 7-13.

15. Gao, D., Tang, T., Zhu, J., Tang, Y., Sun, H. \& Li, S. 2019. CXCL12 has therapeutic value in facial nerve injury and promotes Schwann cells autophagy and migration via PI3K-AKT-mTOR signal pathway. Int J Biol Macromol, 124, 460-468.

16. GÜmbel, D., Suchy, B., Wien, L., Gelbrich, N., Napp, M., Kramer, A., Ekkernkamp, A., Daeschlein, G. \& Stope, M. B. 2017. Comparison of Cold Atmospheric Plasma Devices' Efficacy on Osteosarcoma and Fibroblastic In Vitro Cell Models. Anticancer Res, 37, 5407-5414.

17. Haertel, B., Von Woedtke, T., Weltmann, K. D. \& Lindequist, U. 2014. Non-thermal atmosphericpressure plasma possible application in wound healing. Biomol Ther (Seoul), 22, 477-490.

18. Haralambiev, L., Nitsch, A., Jacoby, J. M., Strakeljahn, S., Bekeschus, S., Mustea, A., Ekkernkamp, A. \& Stope, M. B. 2020. Cold Atmospheric Plasma Treatment of Chondrosarcoma Cells Affects Proliferation and Cell Membrane Permeability. Int J Mol Sci, 21, 2291.

19. Hartwig, S., Preissner, S., Voss, J. O., Hertel, M., Doll, C., Waluga, R. \& Raguse, J. D. 2017. The feasibility of cold atmospheric plasma in the treatment of complicated wounds in cranio-maxillofacial surgery. J Craniomaxillofac Surg, 45, 1724-1730.

20. Hasse, S., Duong Tran, T., Hahn, O., Kindler, S., Metelmann, H. R., Von Woedtke, T. \& Masur, K. 2016. Induction of proliferation of basal epidermal keratinocytes by cold atmospheric-pressure plasma. Clin Exp Dermatol, 41, 202-9.

21. He, R., Li, Q., Shen, W., Wang, T., Lu, H., Lu, J., Lu, F., Luo, M., Zhang, J., Gao, H., Wang, D., Xing, W., Jia, W. \& Liu, F. 2020. The efficacy and safety of cold atmospheric plasma as a novel therapy for diabetic wound in vitro and in vivo. Int Wound $\mathrm{J}, 17,851-863$.

22. Hoffmann, C., Berganza, C. \& Zhang, J. 2013. Cold Atmospheric Plasma: methods of production and application in dentistry and oncology. Med Gas Res, 3, 21.

23. Ishii, A., Furusho, M., Macklin, W. \& Bansal, R. 2019. Independent and cooperative roles of the Mek/ERK1/2-MAPK and PI3K/Akt/mTOR pathways during developmental myelination and in adulthood. Glia, 67, 1277-1295.

24. Islam, M. T. 2017. Oxidative stress and mitochondrial dysfunction-linked neurodegenerative disorders. Neurol Res, 39, 73-82.

25. Izadjoo, M., Zack, S., Kim, H. \& Skiba, J. 2018. Medical applications of cold atmospheric plasma: state of the science. J Wound Care, 27, S4-S10. 
26. Jessen, K. R. \& Mirsky, R. 2016. The repair Schwann cell and its function in regenerating nerves. $J$ Physiol, 594, 3521-3531.

27. Juliana Šimončicová, Svetlana Kryštofová, Veronika Medvecká, Kamila Ďurišová \& Kaliňáková, B. 2019. Technical applications of plasma treatments: current state and perspectives. Appl. Microbiol Biotechnol, 103, 5117-5129.

28. Kalghatgi, S., Friedman, G., Fridman, A. \& Clyne, A. M. 2010. Endothelial cell proliferation is enhanced by low dose non-thermal plasma through fibroblast growth factor-2 release. Ann Biomed Eng, 38, 748-757.

29. Kalyanaraman, B., Hardy, M., Podsiadly, R., Cheng, G. \& Zielonka, J. 2017. Recent developments in detection of superoxide radical anion and hydrogen peroxide: Opportunities, challenges, and implications in redox signaling. Arch Biochem Biophys, 617, 38-47.

30. Kartaschew, K., Mischo, M., Baldus, S., Bründermann, E., Awakowicz, P. \& Havenith, M. 2015. Unraveling the interactions between cold atmospheric plasma and skin-components with vibrational microspectroscopy. Biointerphases, 10, 029516.

31. Kleineidam, B., Nokhbehsaim, M., Deschner, J. \& Wahl, G. 2019. Effect of cold plasma on periodontal wound healing-an in vitro study. Clin Oral Investig, 23, 1941-1950.

32. Li, R., Liu, Z., Pan, Y., Chen, L., Zhang, Z. \& Lu, L. 2014. Peripheral nerve injuries treatment: a systematic review. Cell Biochem Biophys, 68, 449-454.

33. Liu, J. R., Xu, G. M., Shi, X. M. \& Zhang, G. J. 2017. Low temperature plasma promoting fibroblast proliferation by activating the NF-KB pathway and increasing cyclinD1 expression. Sci Rep, 7, 11698.

34. Lou, B. S., Hsieh, J. H., Chen, C. M., Hou, C. W., Wu, H. Y., Chou, P. Y., Lai, C. H. \& Lee, J. W. 2020. Helium/Argon-Generated Cold Atmospheric Plasma Facilitates Cutaneous Wound Healing. Front Bioeng Biotechnol, 8, 683.

35. Luo, Z., Xu, X., Sho, T., Zhang, J., Xu, W., Yao, J. \& Xu, J. 2019. ROS-induced autophagy regulates porcine trophectoderm cell apoptosis, proliferation, and differentiation. Am J Physiol Cell Physiol, 316, C198-C209.

36. Maurel, P. \& Salzer, J. L. 2000. Axonal regulation of Schwann cell proliferation and survival and the initial events of myelination requires PI 3-kinase activity. J Neurosci, 20, 4635-4645.

37. Miletić, M., Mojsilović, S., Okić Đorđević, I., Maletić, D., Puač, N., Lazović, S., Malović, G., Milenković, P., Lj Petrović, Z. \& Bugarski, D. 2013. Effects of non-thermal atmospheric plasma on human periodontal ligament mesenchymal stem cells. Journal of Physics D: Applied Physics, 46, 345401.

38. Mo, C., Shetti, D. \& Wei, K. 2019. Erianin Inhibits Proliferation and Induces Apoptosis of HaCaT Cells via ROS-Mediated JNK/c-Jun and AKT/mTOR Signaling Pathways. Molecules, 24, 2727.

39. Namgung, U. 2014. The role of Schwann cell-axon interaction in peripheral nerve regeneration. Cells Tissues Organs, 200, 6-12.

40. Nissanka, N. \& Moraes, C. T. 2018. Mitochondrial DNA damage and reactive oxygen species in neurodegenerative disease. FEBS Lett, 592, 728-742. 
41. O'connor, N., Cahill, O., Daniels, S., Galvin, S. \& Humphreys, H. 2014. Cold atmospheric pressure plasma and decontamination. Can it contribute to preventing hospital-acquired infections? J Hosp Infect, 88, 59-65.

42. Ogata, T., Yamamoto, S., Nakamura, K. \& Tanaka, S. 2006. Signaling axis in schwann cell proliferation and differentiation. Mol Neurobiol, 33, 51-62.

43. Oláh, G., Módis, K., Törö, G., Hellmich, M. R., Szczesny, B. \& Szabo, C. 2018. Role of endogenous and exogenous nitric oxide, carbon monoxide and hydrogen sulfide in HCT116 colon cancer cell proliferation. Biochem Pharmacol, 149, 186-204.

44. Park, K. K., Liu, K., Hu, Y., Smith, P. D., Wang, C., Cai, B., Xu, B., Connolly, L., Kramvis, I., Sahin, M. \& He, Z. 2008. Promoting axon regeneration in the adult CNS by modulation of the PTEN/mTOR pathway. Science, 322, 963-966.

45. Przekora, A., Pawlat, J., Terebun, P., Duday, D., Canal, C., Hermans, S., Audemar, M., Labay, C., Thomann, J.-S. \& Ginalska, G. 2019. The effect of low temperature atmospheric nitrogen plasma on MC3T3-E1 preosteoblast proliferation and differentiation in vitro. Journal of Physics D: Applied Physics, 52, 275401.

46. Qi, Y., Wang, S., Luo, Y., Huang, W., Chen, L., Zhang, Y., Liang, X., Tang, J., Zhang, Y., Zhang, L., Chao, F., Gao, Y., Zhu, Y. \& Tang, Y. 2020. Exercise-induced Nitric Oxide Contributes to Spatial Memory and Hippocampal Capillaries in Rats. Int J Sports Med, 41, 951-961.

47. Rbia, N. \& Shin, A. Y. 2017. The Role of Nerve Graft Substitutes in Motor and Mixed Motor/Sensory Peripheral Nerve Injuries. J Hand Surg Am, 42, 367-377.

48. Rezaei, F., Vanraes, P., Nikiforov, A., Morent, R. \& De Geyter, N. 2019. Applications of Plasma-Liquid Systems: A Review. Materials (Basel), 12, 2751.

49. Safa, B. \& Buncke, G. 2016. Autograft Substitutes: Conduits and Processed Nerve Allografts. Hand Clin, 32, 127-140.

50. Sardella, E., Mola, M. G., Gristina, R., Piccione, M., Veronico, V., Bellis, M., Cibelli, A., Buttiglione, M., Armenise, V., Favia, P. \& Nicchia, G. P. 2020. A Synergistic Effect of Reactive Oxygen and Reactive Nitrogen Species in Plasma Activated Liquid Media Triggers Astrocyte Wound Healing. Int J Mol Sci, $21,3343$.

51. Semmler, M. L., Bekeschus, S., Schafer, M., Bernhardt, T., Fischer, T., Witzke, K., Seebauer, C., Rebl, H., Grambow, E., Vollmar, B., Nebe, J. B., Metelmann, H. R., Woedtke, T. V., Emmert, S. \& Boeckmann, L. 2020. Molecular Mechanisms of the Efficacy of Cold Atmospheric Pressure Plasma (CAP) in Cancer Treatment. Cancers (Basel), 12, 269.

52. Sies, H. \& Jones, D. P. 2020. Reactive oxygen species (ROS) as pleiotropic physiological signalling agents. Nat Rev Mol Cell Biol, 21, 363-383.

53. Song, W., Wang, E., Gao, Y., Wu, Q., Rao, S., Wang, H. \& Bao, L. 2018. Low temperature plasma induced apoptosis in CNE-2Z cells through endoplasmic reticulum stress and mitochondrial dysfunction pathways. Plasma Processes and Polymers, 15, 1600249. 
54. Sun, W., Wang, B., Qu, X. L., Zheng, B. Q., Huang, W. D., Sun, Z. W., Wang, C. M. \& Chen, Y. 2019. Metabolism of Reactive Oxygen Species in Osteosarcoma and Potential Treatment Applications. Cells, 9, 87.

55. Tarabova, B., Lukes, P., Hammer, M. U., Jablonowski, H., Von Woedtke, T., Reuter, S. \& Machala, Z. 2019. Fluorescence measurements of peroxynitrite/peroxynitrous acid in cold air plasma treated aqueous solutions. Phys Chem Chem Phys, 21, 8883-8896.

56. Wiegand, C., Fink, S., Hipler, U. C., Beier, O., Horn, K., Pfuch, A., Schimanski, A. \& Grünler, B. 2017. Cold atmospheric pressure plasmas exhibit antimicrobial properties against critical bacteria and yeast species. J Wound Care, 26, 462-468.

57. Xu, G. M., Shi, X. M., Cai, J. F., Chen, S. L., Li, P., Yao, C. W., Chang, Z. S. \& Zhang, G. J. 2015. Dual effects of atmospheric pressure plasma jet on skin wound healing of mice. Wound Repair Regen, 23, 878-84.

58. Xu, S., Wang, Y., Que, Y., Ma, C., Cai, S., Wang, H., Yang, X., Yang, C., Cheng, C., Zhao, G. \& Hu, Y. 2020. Cold Atmospheric plasma-activated Ringer's Solution Inhibits the Proliferation of Osteosarcoma Cells Through the Mitochondrial Apoptosis Pathway. Oncol Rep, 43, 1683-1691.

59. Yan, D., Sherman, J. H. \& Keidar, M. 2017. Cold atmospheric plasma, a novel promising anti-cancer treatment modality. Oncotarget, 8, 15977-15995.

60. Yao, W., Lin, Z., Shi, P., Chen, B., Wang, G., Huang, J., Sui, Y., Liu, Q., Li, S., Lin, X., Liu, Q. \& Yao, H. 2020. Delicaflavone induces ROS-mediated apoptosis and inhibits PI3K/AKT/mTOR and Ras/MEK/Erk signaling pathways in colorectal cancer cells. Biochem Pharmacol, 171, 113680.

61. Zhang, H., Zhang, J., Ma, J., Shen, J., Lan, Y., Liu, D., Xia, W., Xu, D. \& Cheng, C. 2020a. Differential sensitivities of HeLa and MCF-7 cells at G1-, S-, G2- and M-phase of the cell cycle to cold atmospheric plasma. Journal of Physics D: Applied Physics, 53, 125202.

62. Zhang, N., Diao, Y., Hua, R., Wang, J., Han, S., Li, J. \& Yin, Y. 2017. Nitric oxide-mediated pathways and its role in the degenerative diseases. Front Biosci (Landmark Ed), 22, 824-834.

63. Zhang, Y., Xiao, Y., Ma, Y., Liang, N., Liang, Y., Lu, C. \& Xiao, F. 2020b. ROS-mediated miR-21-5p regulates the proliferation and apoptosis of $\mathrm{Cr}(\mathrm{VI})$-exposed $\mathrm{L} 02$ hepatocytes via targeting PDCD4. Ecotoxicol Environ Saf, 191, 110160.

\section{Figures}


A
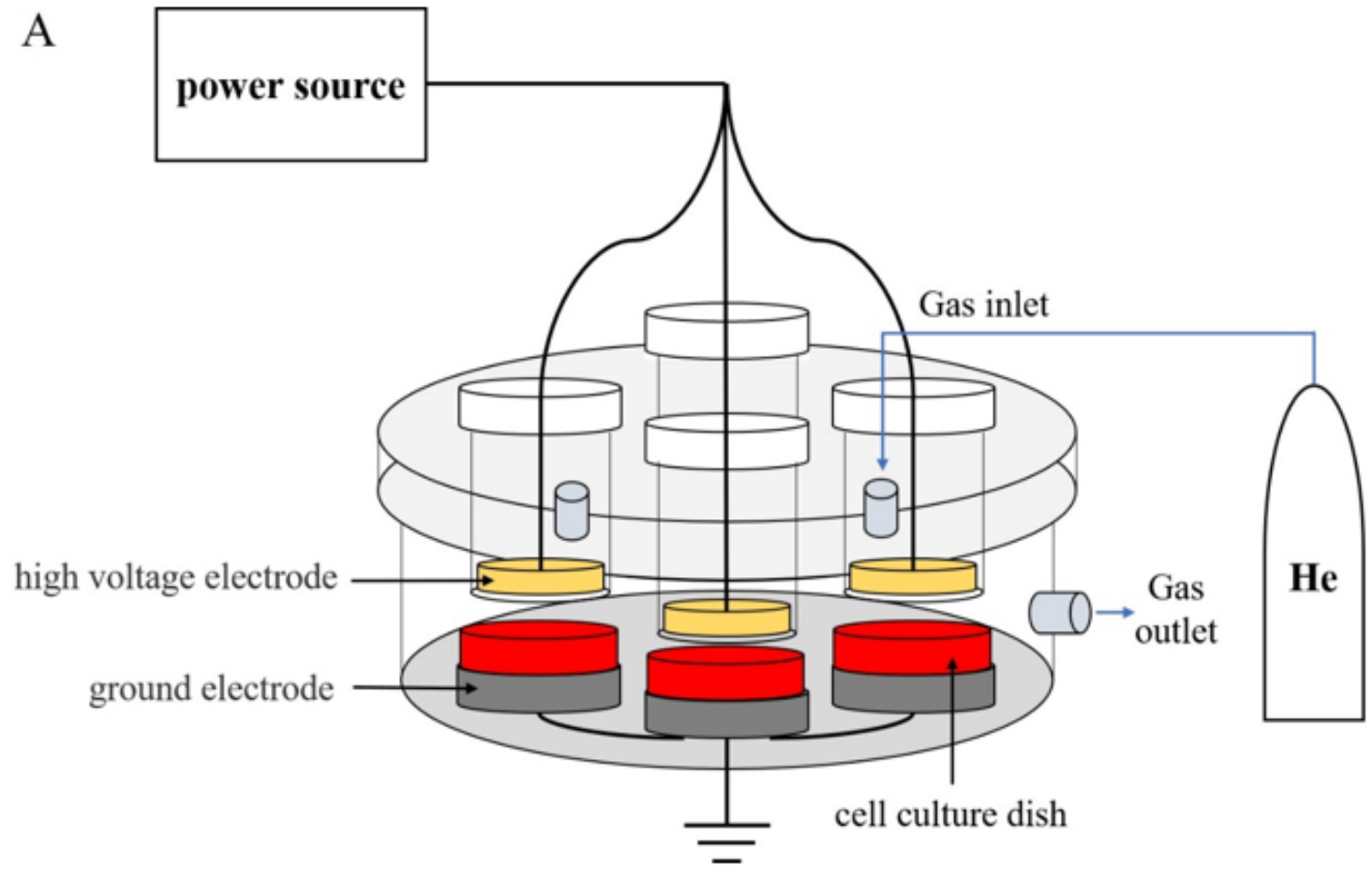

B

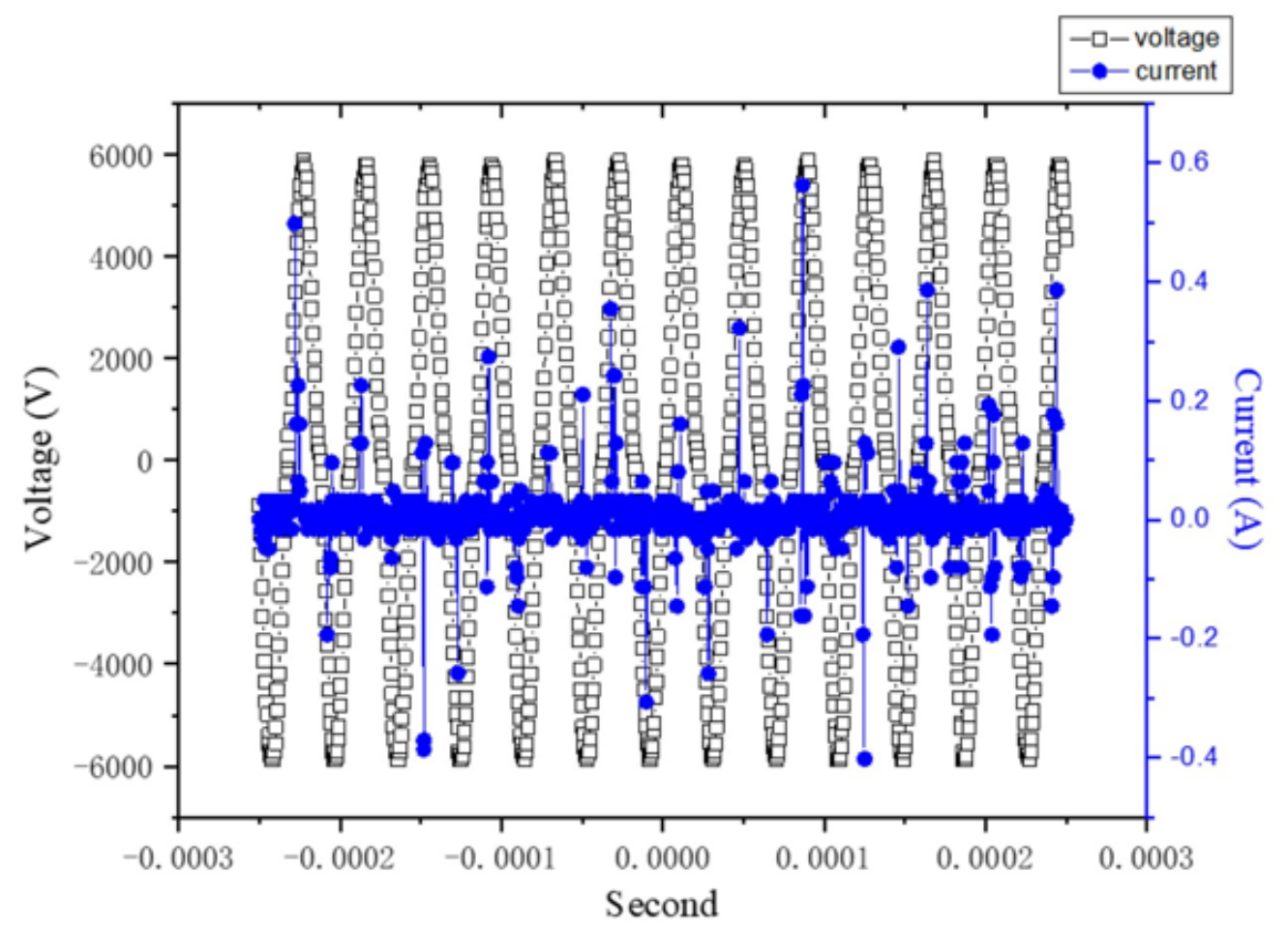

Figure 1

(A) Schematic diagram of the DBD plasma device. (B) The voltage and current profiles of the DBD plasma device. 

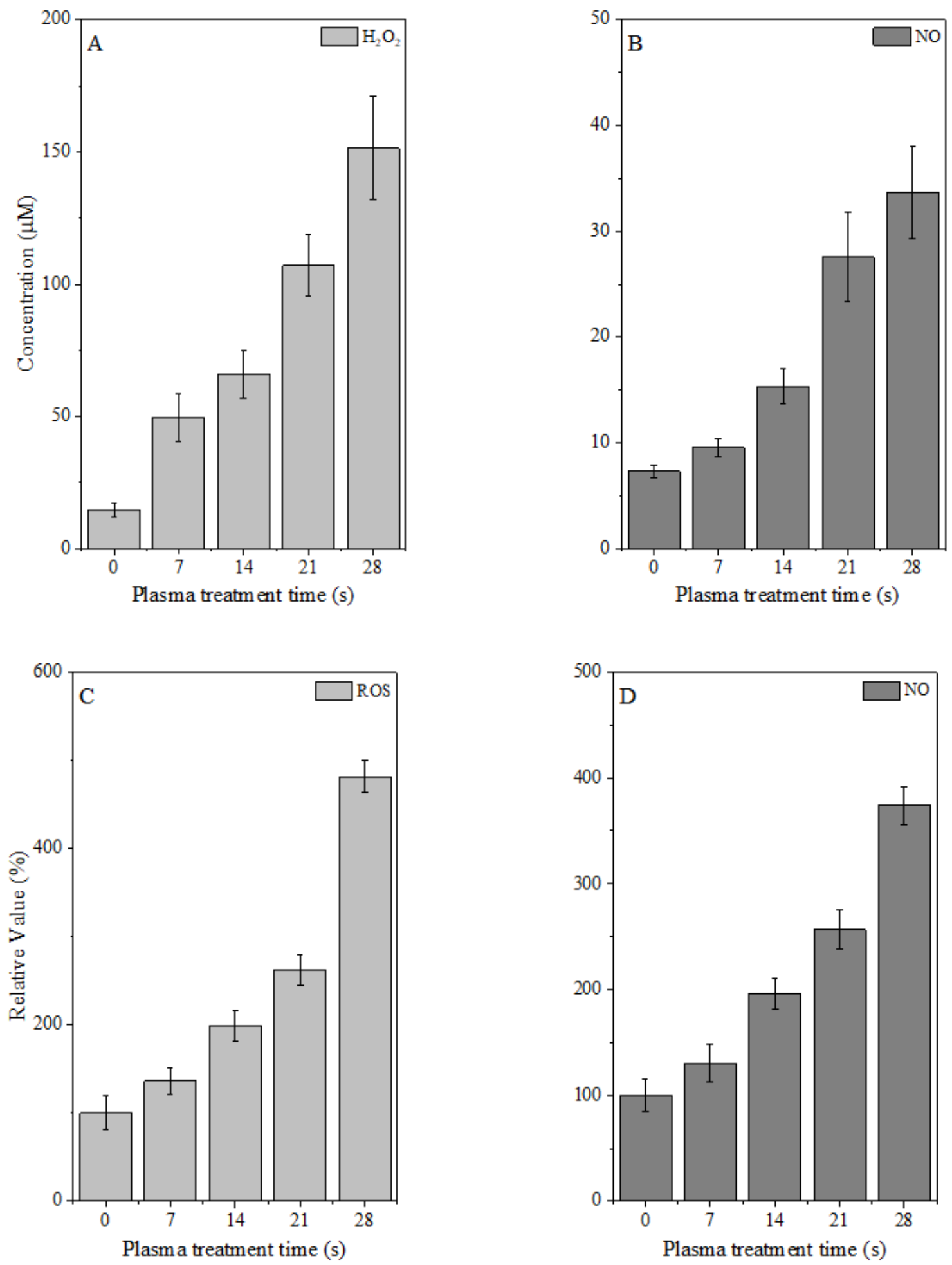

Figure 2

The concentration of $\mathrm{H} 2 \mathrm{O} 2$ and $\mathrm{NO}$ in cell culture medium after plasma irradiation for different time, and the production of intracellular $\mathrm{H} 2 \mathrm{O} 2$ and $\mathrm{NO}$ induced by plasma were detected 24 hours after treatment. (A), (B) The concentration of H2O2 and NO in DMEM. (C), (D) The relative fluorescence intensity of intracellular $\mathrm{H} 2 \mathrm{O} 2$ and $\mathrm{NO}$. 

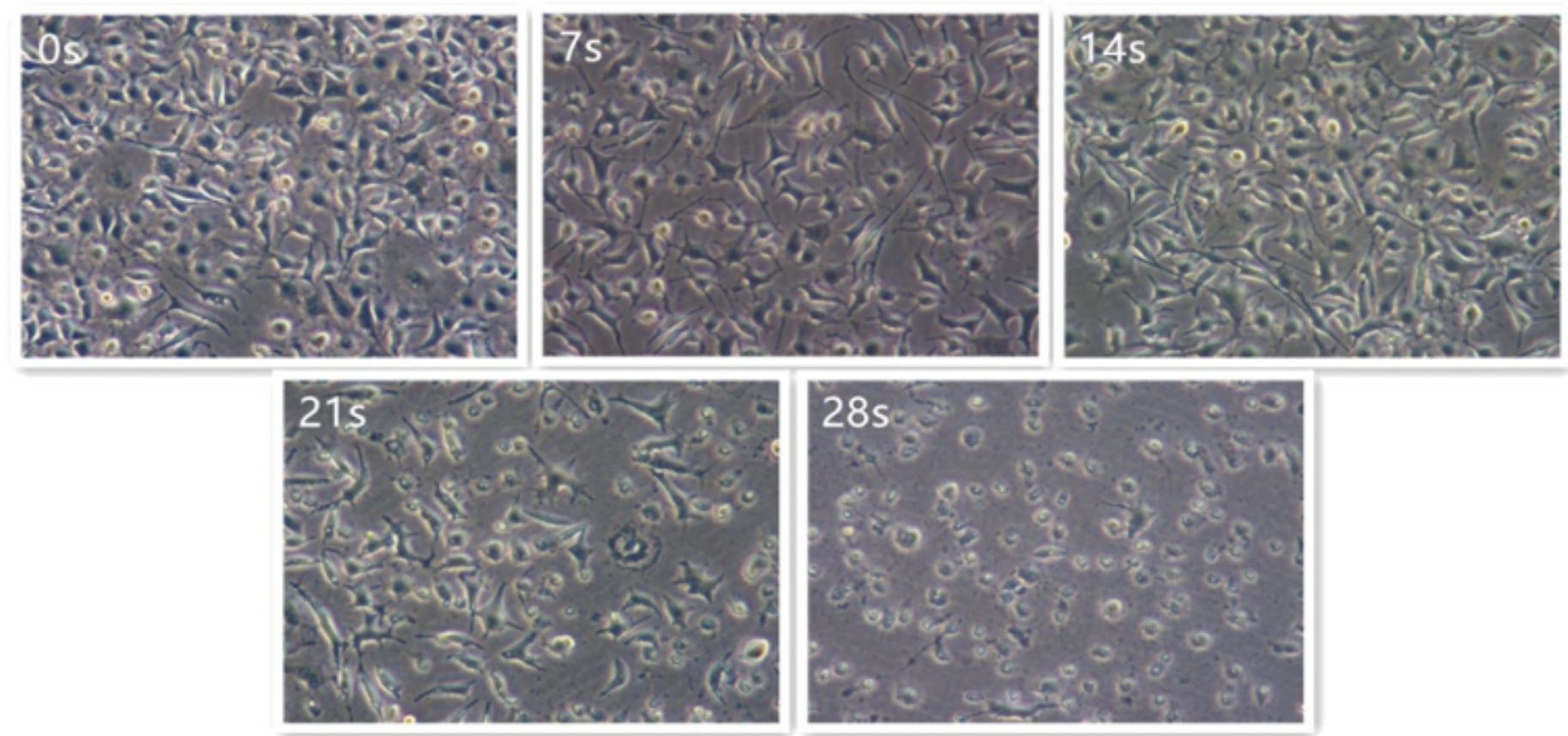

\section{Figure 3}

The SCs morphology after plasma treatment for different time. 


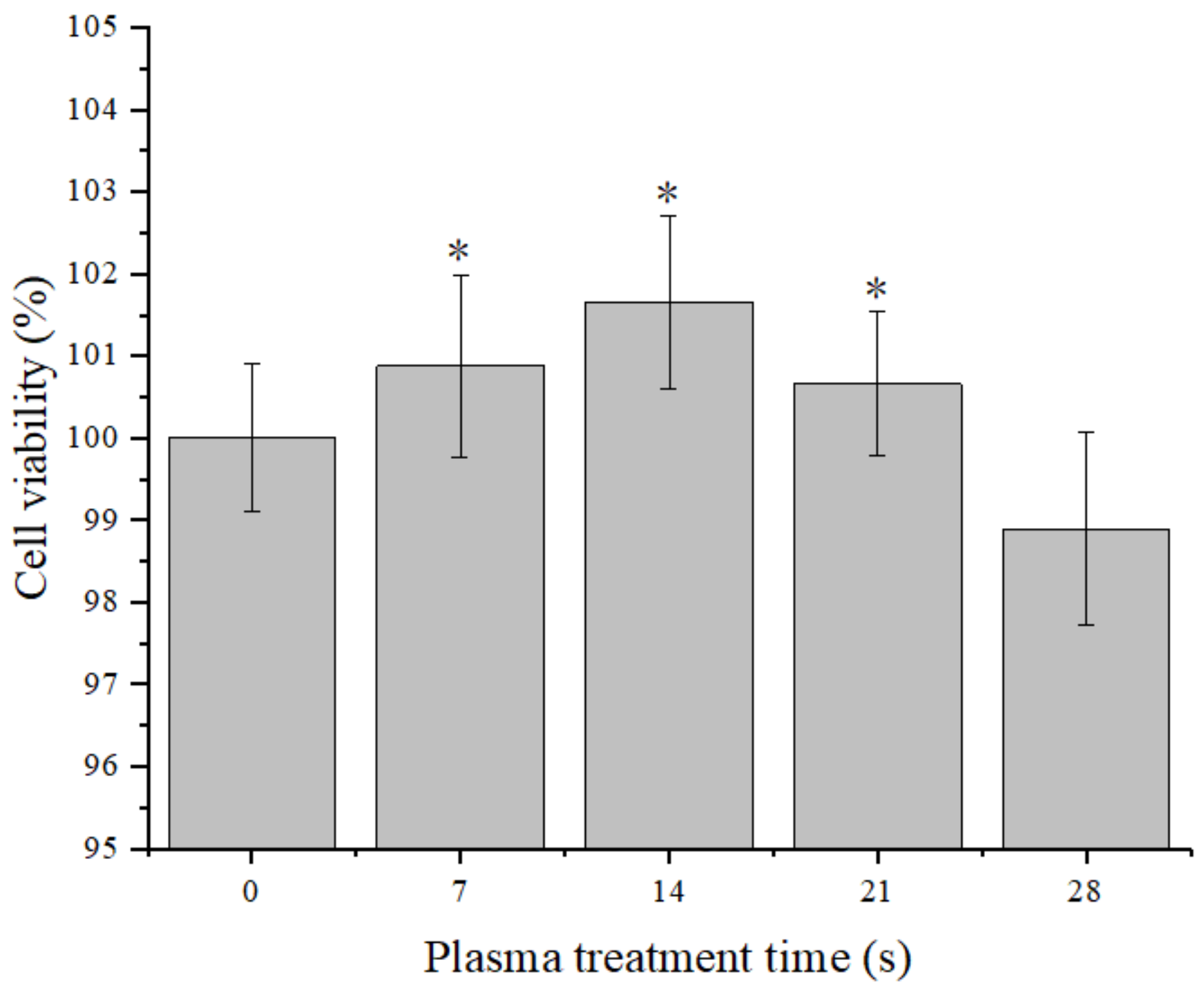

Figure 4

Cell viability of SCs after plasma treatment for different time. ${ }^{*} \mathrm{P}<0.05$. 

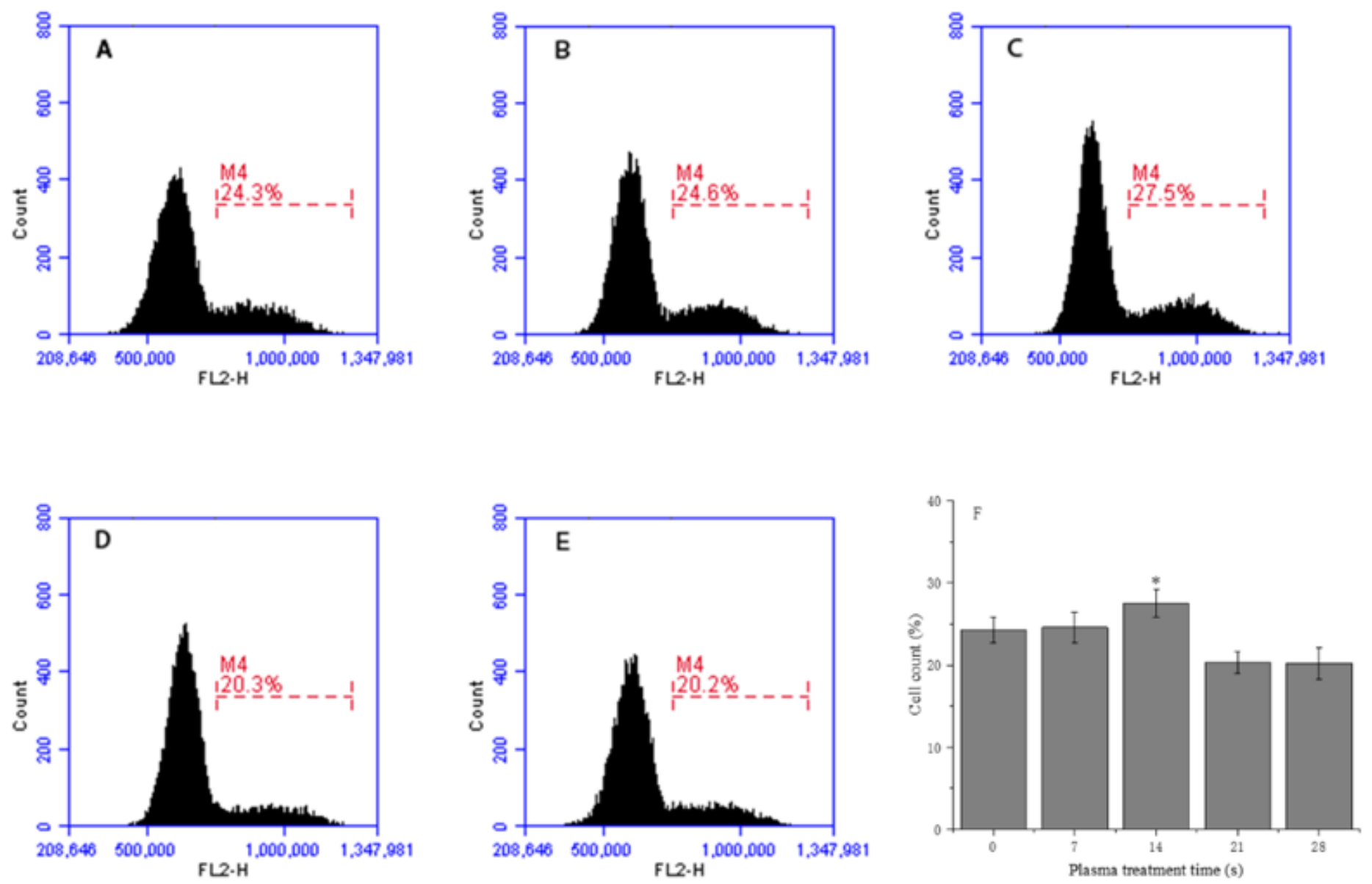

Figure 5

Cell cycle distribution of SCs after plasma treatment for different time. (A-E) The graphs are in order of 0 $\mathrm{s}, 7 \mathrm{~s}, 14 \mathrm{~s}, 21 \mathrm{~s}$, and $28 \mathrm{~s}$, and the red line indicates the ratio of S+G2/M phase. (F) Quantitative analysis and comparison of $\mathrm{S}+\mathrm{G} 2 / \mathrm{M}$ phase ratio of $\mathrm{SCs}$ after plasma treatment for different time. ${ }^{*} \mathrm{P}<0.05$. 
A
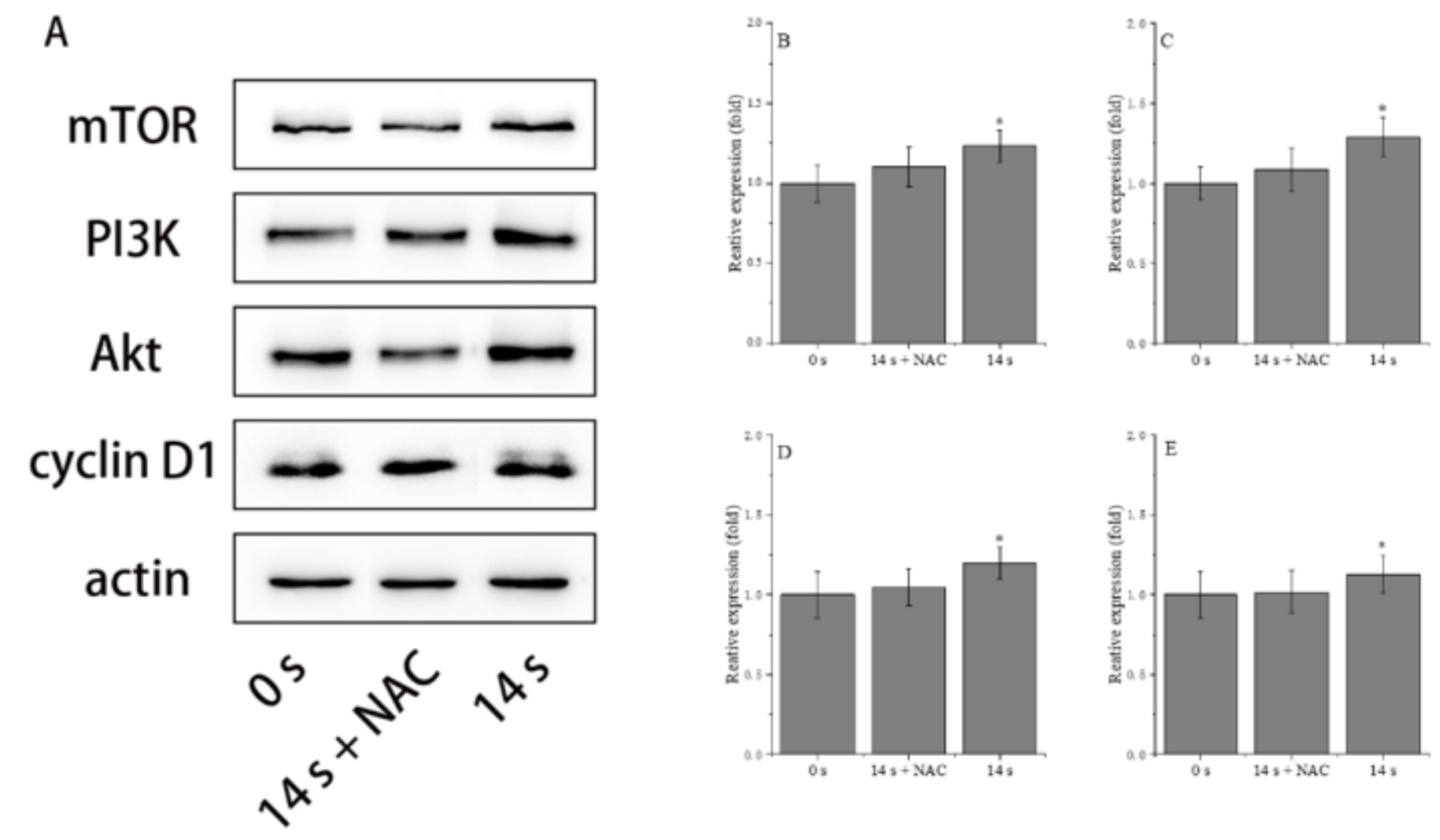

\section{Figure 6}

The expression of related proteins was detected by western blot. (A) Western blot results of the three groups ( $0 \mathrm{~s}, 14 \mathrm{~s}+\mathrm{NAC}$ and $14 \mathrm{~s})$. (B) Changes of mTOR/actin ratio in SCs treated with CAP. (C) Changes of PI3K/actin ratio in SCs treated with CAP. (D) Changes of Akt/actin ratio in SCs treated with CAP. (E) Changes of cyclinD1/actin ratio in SCs treated with CAP. ${ }^{*} \mathrm{P}<0.05$. 


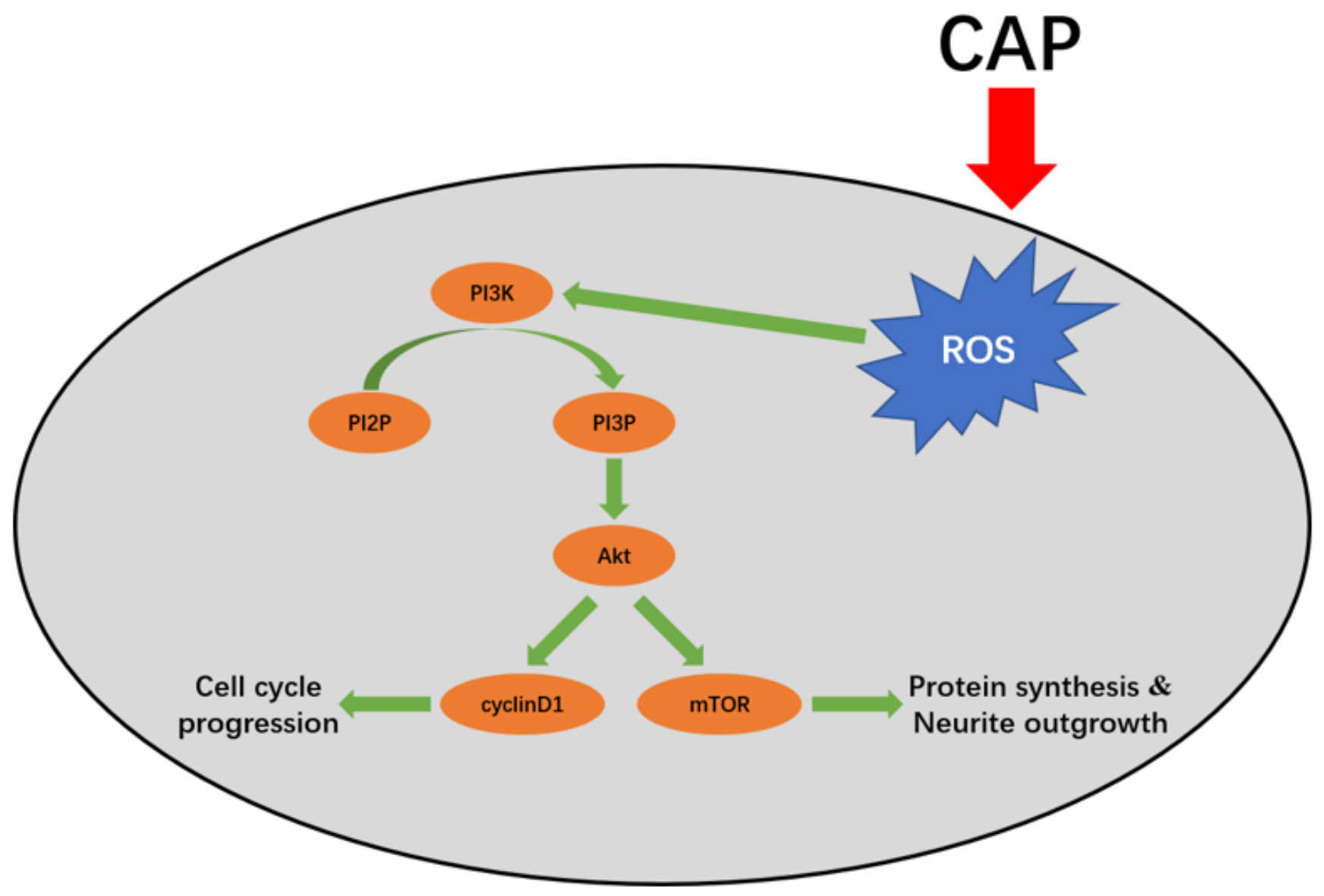

Figure 7

Schematic diagram of this study. Cold atmospheric plasma (CAP) may promote SCs proliferation through the PI3K/Akt/mTOR pathway. 